\title{
OPEN Swedish intrauterine growth reference ranges of biometric measurements of fetal head, abdomen and femur
}

\author{
Linda Lindström $\mathbb{1}^{1 \bowtie}$, Mårten Ageheim ${ }^{1}$, Ove Axelsson ${ }^{1,2}$, Laith Hussain-Alkhateeb ${ }^{3}$, \\ Alkistis Skalkidou ${ }^{1} \&$ Eva Bergman ${ }^{1}$
}

Ultrasonic assessment of fetal growth is an important part of obstetric care to prevent adverse pregnancy outcome. However, lack of reliable reference ranges is a major barrier for accurate interpretation of the examinations. The aim of this study was to create updated Swedish national reference ranges for intrauterine size and growth of the fetal head, abdomen and femur from gestational week 12 to 42 . This prospective longitudinal multicentre study included 583 healthy pregnant women with low risk of aberrant fetal growth. Each woman was examined up to five times with ultrasound from gestational week $12+3$ to $41+6$. The assessed intrauterine fetal biometric measurements were biparietal diameter (outer-inner), head circumference, mean abdominal diameter, abdominal circumference and femur length. A two-level hierarchical regression model was employed to account for the individual measurements of the fetus and the number of repeated visits for measurements while accounting for the random effect of the identified parameterization of gestational age. The expected median and variance, expressed in both standard deviations and percentiles, for each individual biometric measurement was calculated. The presented national reference ranges can be used for assessment of intrauterine size and growth of the fetal head, abdomen and femur in the second and third trimester of pregnancy.

Fetal growth is an intricate process, depending on multiple factors, genetic as well as environmental. Fetal growth restriction is closely related to mortality and morbidity, with increased risks of short and long term complications ${ }^{1}$. A correct assessment of fetal size and growth is important to identify fetuses at risk of unfavourable outcomes ${ }^{2}$. In order to correctly assess fetal size, a reliable standard is of paramount importance.

An appropriate study design is vital when new standards for fetal size and growth are constructed, as fetal growth should not be assessed using charts that originate from cross-sectional data. Standards for fetal growth are instead ideally created from longitudinal data with repeated measurements over time in pregnancies with accurate pregnancy dating ${ }^{3,4}$. During the last decade, several international growth standards have been created $^{5-8}$. However, doubts have been raised regarding the applicability of these international standards when evaluated in different populations ${ }^{7,9-11}$. It has therefore been advised that the international standards should be evaluated in each separate population before taken into general practice ${ }^{5}$.

The current Scandinavian growth charts, created in 1996 by Maršál et al., lack data on gestational ages below 25 weeks and are based on data from a rather small number of women, only 86, of whom $24 \%$ were smokers ${ }^{12}$. Since then, demographics of the Swedish pregnant population have changed, including e.g. higher maternal BMI, fewer smokers and higher birthweights ${ }^{13}$. Further, obstetric interventions are nowadays performed even in the second trimester of pregnancy, and children born preterm can be saved as early as gestational week 22 . Hence, there is a pressing need for updated Swedish charts for fetal size and growth.

The aim of this study was to create updated national reference ranges for fetal size and growth from gestational week 12 to 42, by applying modern statistical methods to longitudinally collected data on ultrasonically derived intrauterine biometric measurements in a large Swedish cohort of low-risk pregnancies.

${ }^{1}$ Department of Women's and Children's Health, Uppsala University, Uppsala, Sweden. ${ }^{2}$ Centre for Clinical Research Sörmland, Uppsala University, Eskilstuna, Sweden. ${ }^{3} \mathrm{Global}$ Health, School of Public Health and Community Medicine, Institute of Medicine, Sahlgrenska Academy, University of Gothenburg, Gothenburg, Sweden. ${ }^{\square}$ email: linda.lindstrom@kbh.uu.se 


\section{Methods}

Study design and population. In this prospective longitudinal multicenter study, 684 women were recruited in early pregnancy between September 2015 and September 2018 in five sites in central Sweden; Uppsala, Falun, Katrineholm, Västerås and Örebro. At first antenatal visit, all women who received antenatal care at 18 representative primary care units were invited to participate. The participants were recruited from urban as well as rural areas. Healthy, non-smoking women were eligible if they had regular menstrual periods ( $28 \pm 4$ days) and no previous pregnancy complications, such as preterm birth, pre-eclampsia, eclampsia, gestational diabetes, hypertension and stillbirth. Women with chronic hypertension, systemic lupus erythematosus, kidney disease, diabetes, previous gastric bypass surgery or inflammatory bowel disease were not eligible, as these conditions are known to affect fetal growth.

At first study visit, between pregnancy week $12+3$ and $13+6$ according to the last menstrual period, gestational age (GA) was assessed with ultrasound. Only women with spontaneously conceived singleton pregnancies were recruited, and the discrepancy between GA according to the biparietal diameter (BPD) and GA according to last menstrual period was not allowed to exceed seven days. Seven experienced sonographers performed the study scans. Before first inclusion, all sonographers were given detailed instructions regarding how the biometric measurements should be performed.

At inclusion, the women were randomized to nine study protocols, according to the timing of the follow-up visits, in which each subject was assigned four follow-up ultrasound scans between gestational week 14 and 41 . The study protocols were kept in closed envelopes and were randomly assigned to each study subject. The purpose was to receive evenly distributed measurements among the GAs. The vast majority of Swedish pregnant women undergo a routine second trimester ultrasound scan, usually taking place between week 17 and 20. In cases where the study subject was not randomized to a scan in week 17 to 20 (five protocols), biometric measurements were recorded in the study database if the scan was performed by a study sonographer. In order to compensate for the expected decline in the number of women with ongoing pregnancies, a larger number of study subjects were assigned to each group for the scans in week $37-41$.

Women were excluded from the study if the pregnancy was complicated by gestational hypertension, preeclampsia or eclampsia, gestational diabetes, placenta previa, fetal malformations or chromosomal aberrations, stillbirth, fetal growth restriction with abnormal fetal Doppler or birth before $37+0$ gestational weeks (259 gestational days).

Procedures. The ultrasound machines used were GE Voluson E10, GE Voluson E8 and GE Voluson E6 with abdominal transducers 2-6 MHz RM6C, 2-8 MHz C4-8-D, RAB 4-8-D and 2-9 MHz C2-9-D. BPD was used to calculate the GA, using the modified Selbing and Kjessler formula, $58.65+1.07^{\star} \mathrm{BPD}+0.0138^{\star} \mathrm{BPD}^{2}$, as recommended by the Swedish Society of Obstetrics and Gynecology ${ }^{14}$. Only fetuses with BPD at least $21 \mathrm{~mm}$ at first study visit were included. At each ultrasound scan, five biometric measurements were each measured three times; BPD, head circumference (HC), mean abdominal diameter (MAD), abdominal circumference (AC) and femur length (FL). All data was manually registered in a web-based study database.

$\mathrm{BPD}$ and $\mathrm{HC}$ were measured in an axial section, at the level of the thalami, with the midline echo in a central position broken anteriorly by cavum septum pellucidum. Orbitae and cerebellum were non-visible. The callipers for BPD were placed on the outer margin of the proximal parietal bone, and the inner margin of the distal parietal bone. HC was measured by placing the callipers on the outer borders of the frontal and occipital edges of the bone, and the ellipse facility was used to follow the contour of the skull. MAD and AC were measured in cross-section (circular view of the abdomen), with the stomach visible, the umbilical vein in the anterior third of the abdomen and the aorta and inferior vena cava anteriorly of the spine. Further, the greater part of a rib should be seen but not the heart or kidneys. The callipers for MAD were placed on the outer skin borders both anterioposteriorly and perpendicular transversely. AC was measured using the ellipse facility to follow the outer contours of the skin. Lastly, FL was measured in a longitudinal section of the femur in $45^{\circ}$ to $90^{\circ}$ angle of insonation, with the callipers placed on the outer borders of the femoral diaphysis. All measurements followed the national recommendations for biometric assessment and the practice guidelines from The International Society of Ultrasound in Obstetrics and Gynecology $y^{14,15}$.

Data management. Each biometric measurement was estimated three times and registered in the study database for all GAs, totalling to 38,601 repeated measurements. Data was first examined graphically using scatter-plots of each biometric parameter for GA in order to identify deviant records and inspect some data assumptions. Outliers were identified and each outlier was inspected regarding GA and the value of the individual biometric parameters. GA was evaluated and corrected against wrong data entry in the database. Incorrect GA records were adjusted during the examination process according to estimated date of delivery and date of examination. Next, extreme or unreasonable measurements (such as HC equal to or smaller than BPD) were deleted or otherwise corrected, if original measurements were available in the woman's medical records (often available for women examined in Uppsala, unlike other study sites). Where original measurements were considered unreasonable or contradictory, the corresponding data was deleted.

In 22 out of total 33 measurement records with incorrect GA, there was no information on GA. In the remaining eleven cases, GA was incorrectly calculated. A total of 267 measurements $(0.68 \%)$ were outliers, with suspected incorrect entry of measurement values. Of the incorrect values, 166 (62\%) were deleted. The remaining 101 incorrect values were corrected based on original measurement data. BPD was the measurement with lowest rate of incorrect values, $0.35 \%$, followed by MAD with $0.41 \%$ incorrect values. AC was the measurement with the highest rate of incorrect values, $1.19 \%$, followed by $\mathrm{HC}$ with a rate of $0.84 \%$. FL was incorrectly entered in $0.64 \%$ of the measurements. 


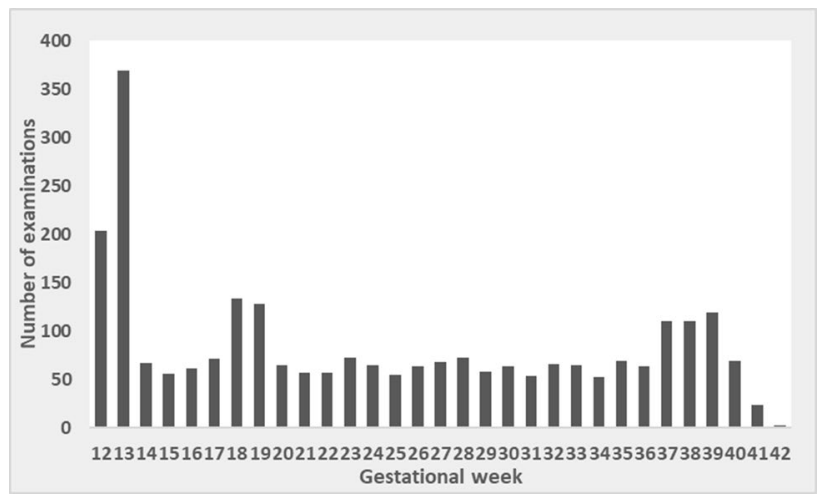

Figure 1. Distribution of ultrasound examinations by gestational age.

Repeatability and reproducibility. A repeatability and reproducibility study was performed, where five study subjects were examined with repeated ultrasound scans during the same day. Six out of seven sonographers participated. Each study subject was examined two or three times by different sonographers, who assessed all five biometric measurements three times during each scan.

A linear mixed effect model was applied to estimate inter-observer variation. The chosen model accounts for the repeated measures and the differences in biometric measurements due to differences in GA. The model included fixed and random effects for each biometric measurement (BPD, HC, MAD, AC and FL), with a statistical marginal error of $5 \%$.

In addition, the intraclass correlation coefficient (ICC) was assessed by applying a two-way mixed effects model to estimate intra-observer variation. We estimated absolute agreement, which includes systematic and random residual errors, for average measures.

Statistical analysis. Descriptive statistics were used for maternal characteristics at baseline as well as for delivery and neonatal characteristics. An independent samples t-test was performed to evaluate if dating discrepancy was different for girls and boys. The t-test was used after confirming that the data does not violate the test assumptions. A one-way ANOVA was employed to evaluate if dating discrepancy varied between the study sites. An independent samples Mann-Whitney $U$ test was performed to compare median birthweights in subgroups of the cohort.

The biometric measurements were used to create reference ranges for the individual variables (BPD, HC, MAD, HC and FL). The log transformed fetal growth measurements were modelled using a multilevel approach, with fixed and random effects. First, a fractional polynomial regression was performed on the log transformed fetal measurements to identify the best fitting combination of fractional polynomials for the GA. For instance for the fetal BPD, a combination of 0.5 and 3 as the best fitting fractional polynomial powers was identified. The derived parameters were then included in the regression model as fixed effects in a multilevel model to account for repeated measurements for each fetus. We followed the approach used by Ohuma and Altman ${ }^{4}$ and Johnsen et al. ${ }^{16,17}$ - a two-level hierarchical model was used, considering the measurements (level 1) for each fetus (level 2) at each visit with a random effect for the effect of the identified fractional polynomial of GA and the intercept, similar to the study by Johnsen et al. ${ }^{17}$. We used the models mentioned above to estimate the expected fetal measurements at each GA in weeks. Thereafter, similar equations as in ${ }^{17}$ were used to compute the standard deviation (SD) and the percentiles while adjusting for maternal body mass index (BMI), height, parity, county of birth (Nordic or non-Nordic) and fetal sex.

In a sensitivity analysis, where women with abnormal BMI were excluded, we applied the same adjusted statistical models to a subset of the study cohort with BMI 18.5 to $29.9 \mathrm{~kg} / \mathrm{m}^{2}$ to estimate the expected fetal biometric measurements at each GA in weeks, and to compute the SD and percentiles. The reference ranges before and after exclusion of women with abnormal BMI were compared using an independent samples t-test for each biometric measurement, for all subjects as well as stratified according to offspring sex.

Statistical analyses were performed using IBM SPSS Statistics version 2.5 and STATA 15.0.

\section{Results}

Out of the 684 recruited women, 650 were eligible for the study. During pregnancy, 14 women (2.2\%) developed hypertension or pre-eclampsia, and 11 (1.7\%) developed diabetes and were hence excluded. Fetoplacental complications, such as placenta previa, placental abruption, single umbilical artery and preterm fetal growth restriction led to exclusion in six cases. One woman had a late miscarriage, one child was stillborn and 26 children were born preterm. Eight women were excluded due to fetal malformation or chromosomal aberration. Thus, the final cohort consisted of 583 women; 275 from Uppsala, 66 from Falun, 98 from Katrineholm, 50 from Västerås and 94 from Örebro.

In total 2590 ultrasound scans were performed during the study. The majority, 526 of 583 included women, were scanned at least four times. In 187 women, all five planned ultrasound scans were performed. The ultrasound examinations following the dating scan were fairly equally distributed, see Fig. 1 . There was a peak at 


\begin{tabular}{|l|l|l|l|}
\hline Parameter & Median (IQR) & Range & n (\%) \\
\hline Maternal age (years) & $29(26,33)$ & 19,44 & \\
\hline Maternal height $(\mathrm{cm})$ & $167(163,171)$ & 148,187 & \\
\hline Weight first visit $(\mathrm{kg})$ & $66(60,75)$ & 43,146 & \\
\hline Body mass index first visit $\left(\mathrm{kg} / \mathrm{m}^{2}\right)$ & $23.5(21,6,26,5)$ & $16.7,44.8$ & \\
\hline Nordic country of birth & & & $537(92.1 \%)$ \\
\hline Non-European country of birth & & & $32(5.5 \%)$ \\
\hline Smoking first visit & & & 0 \\
\hline Nulliparous & & & $250(42.9 \%)$ \\
\hline Gestational age at inclusion (days) & $92(90,94)$ & 87,101 & \\
\hline Pregnancy duration (days) & $281(276,288)$ & 259,299 & \\
\hline Pregnancy duration (US) in women with spontaneous onset of labour (days) & $282(276,288)$ & 259,298 & \\
\hline Pregnancy duration (LMP) ${ }^{\mathrm{b}}$ in women with spontaneous onset of labour (days) & $281(276,288)$ & 257,301 & \\
\hline Spontaneous vaginal delivery & & & $458(78.6 \%)$ \\
\hline Induction of labour & & & $40(6.9 \%)$ \\
\hline Caesarean section & & & $77(13.2 \%)$ \\
\hline Newborn sex male & & & $308(52.8 \%)$ \\
\hline APGAR $<7$ at 5 min & & & $6(1.0 \%)$ \\
\hline NICU admission>1 day & & & $56(9.6 \%)$ \\
\hline Neonatal death & & & 0 \\
\hline Birthweight $(\mathrm{g})$ & $3625(3344,3925)$ & 2366,5100 \\
\hline Birth length $(\mathrm{cm})$ & $51(50,52)$ & 43,57 & \\
\hline
\end{tabular}

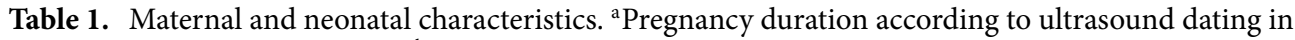

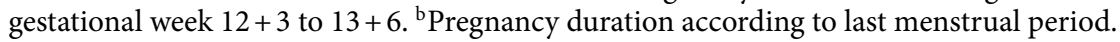

week 18-19, corresponding to the routine ultrasound scan, and week 37-39. The dating discrepancy, i.e. the difference between estimated date of delivery (EDD) according to BPD at first study visit and EDD according to last menstrual period, was within \pm 7 days, and thereby fulfilled the inclusion criteria. The mean discrepancy was -0.1 days (SD 2.8 days) and the median discrepancy was 0 days. The dating discrepancy was slightly, but not statistically significantly, larger for girls than boys $(\mathrm{p}=0.174)$; mean -0.5 days for girls (SD 2.7 days) and 0.2 days for boys (SD 2.7 days), respectively. Further, there was a difference in dating discrepancy between the study sites ( $\mathrm{p}<0.001$ ), with the lowest discrepancy in Katrineholm (mean 0.1 days, SD 2.4 days) and the largest in Västerås (mean - 1.2 days, SD 2.8 days).

The median age of the participating women was 29 years. BMI covered a range of $16.7-44.8 \mathrm{~kg} / \mathrm{m}^{2}$, with a median BMI of $23.5 \mathrm{~kg} / \mathrm{m}^{2}$. The majority of the study population, $92 \%$, were born in a Nordic country (Sweden, Norway, Denmark, Finland or Iceland), and 5.5\% were of non-European origin. Nearly $43 \%$ of the women were nulliparous. The median pregnancy duration was 281 days. Data on neonatal characteristics, including sex, was available for 574 children (98.5\%). The median birthweight was $3625 \mathrm{~g}$ and median birth length $51 \mathrm{~cm}$. For children with a mother born in a Nordic country, the median birthweight was $3628 \mathrm{~g}$, compared with $3600 \mathrm{~g}$ for children with a mother born in a non-Nordic country; a difference that was not statistically significant $(\mathrm{p}=0.258)$. Likewise, the median birthweight was comparable in children with younger and older mothers; $3660 \mathrm{~g}$ for maternal age less than 35 years and $3624.5 \mathrm{~g}$ for maternal age 35 years or older, $\mathrm{p}=0.908$. Nulliparous women gave birth to children with lower median birthweight compared with parous women; $3540 \mathrm{~g}$ for nulliparous and $3714 \mathrm{~g}$ for parous women, $\mathrm{p}=0.008$. Maternal and neonatal characteristics are summarized in Table 1 .

The median and variance of the different biometric measurements for each gestational week are shown in Tables $2,3,4,5,6,7,8,9,10$, and 11 . The variance is expressed in standard deviations $(+3 \mathrm{SD},+2 \mathrm{SD},+1 \mathrm{SD}$, median, -1 SD, -2 SD and $-3 \mathrm{SD})$ and in percentiles $(2.5$ th, 5 th, 10th, 25th, median, 75 th, 90th, 95th and 97.5th).

Table 2 shows the median and variance for estimated BPD by GA in SD, and Table 3 BPD by GA in percentiles. Figure 2a shows the raw data with fitted percentiles for estimated BPD by GA.

Mean and variance equation for BPD in males and females:

$$
E\left(Z_{i}\right)=-2.53+\left[2.47 \log \left(\mathrm{GA}_{\mathrm{i}}\right)\right]+\left[-0.05 \mathrm{GA}_{\mathrm{i}}^{1}\right]
$$

$\operatorname{Var}(Z i)=0.08+\left[0.02 \log \left(\mathrm{GA}_{\mathrm{i}}\right)^{2}\right]+\left[-0.08 \log \left(\mathrm{GA}_{\mathrm{i}}\right)\right]+\left[0.003 \mathrm{GA}_{\mathrm{i}}^{1}\right]+\left[-0.0002 \log \left(\mathrm{GA}_{\mathrm{i}}\right) \mathrm{GA}_{\mathrm{i}}^{1}\right]+\left[0.00004 \mathrm{GA}_{\mathrm{i}}^{2}\right]$

Table 4 shows the median and variance for estimated HC by GA in SD, and Table 5 HC by GA in percentiles. Figure $2 \mathrm{~b}$ shows the raw data with fitted percentiles for estimated HC by GA.

Mean and variance equation for $\mathrm{HC}$ in males and females: 


\begin{tabular}{|c|c|c|c|c|c|c|c|}
\hline GA (weeks ${ }^{\mathrm{a}}$ ) & $-3 \mathrm{SD}$ & $-2 S D$ & -1 SD & Median & $+1 \mathrm{SD}$ & $+2 \mathrm{SD}$ & $+3 \mathrm{SD}$ \\
\hline 12 & 19 & 19 & 20 & 20 & 21 & 21 & 22 \\
\hline 13 & 22 & 22 & 23 & 23 & 24 & 24 & 25 \\
\hline 14 & 25 & 25 & 26 & 27 & 27 & 28 & 29 \\
\hline 15 & 28 & 29 & 29 & 30 & 31 & 32 & 32 \\
\hline 16 & 31 & 32 & 33 & 34 & 34 & 35 & 36 \\
\hline 17 & 34 & 35 & 36 & 37 & 38 & 39 & 40 \\
\hline 18 & 37 & 38 & 39 & 41 & 42 & 43 & 44 \\
\hline 19 & 40 & 41 & 43 & 44 & 45 & 47 & 48 \\
\hline 20 & 43 & 44 & 46 & 48 & 49 & 51 & 53 \\
\hline 21 & 46 & 48 & 49 & 51 & 53 & 55 & 56 \\
\hline 22 & 49 & 51 & 52 & 54 & 56 & 58 & 60 \\
\hline 23 & 52 & 54 & 56 & 58 & 60 & 62 & 64 \\
\hline 24 & 55 & 57 & 59 & 61 & 63 & 65 & 68 \\
\hline 25 & 57 & 59 & 62 & 64 & 66 & 69 & 71 \\
\hline 26 & 60 & 62 & 65 & 67 & 70 & 72 & 75 \\
\hline 27 & 63 & 65 & 67 & 70 & 73 & 75 & 78 \\
\hline 28 & 65 & 67 & 70 & 73 & 75 & 78 & 81 \\
\hline 29 & 67 & 70 & 73 & 75 & 78 & 81 & 84 \\
\hline 30 & 70 & 72 & 75 & 78 & 81 & 84 & 87 \\
\hline 31 & 72 & 75 & 77 & 80 & 83 & 86 & 90 \\
\hline 32 & 74 & 77 & 79 & 82 & 86 & 89 & 92 \\
\hline 33 & 76 & \begin{tabular}{|l|}
79 \\
\end{tabular} & 82 & 85 & 88 & 91 & 94 \\
\hline 34 & 77 & 80 & 83 & 87 & 90 & 93 & 97 \\
\hline 35 & 79 & 82 & 85 & 88 & 92 & 95 & 99 \\
\hline 36 & 81 & 84 & 87 & 90 & 93 & 97 & \begin{tabular}{|l|l}
101 \\
\end{tabular} \\
\hline 37 & 82 & 85 & \begin{tabular}{|l|}
88 \\
\end{tabular} & 92 & 95 & 99 & 102 \\
\hline 38 & 83 & 86 & 90 & 93 & 96 & 100 & 104 \\
\hline 39 & 84 & 87 & 91 & 94 & 98 & 102 & 105 \\
\hline 40 & 85 & \begin{tabular}{|l|}
88 \\
\end{tabular} & 92 & 95 & 99 & 103 & \begin{tabular}{|l|l}
107 \\
\end{tabular} \\
\hline 41 & 86 & 89 & 93 & 96 & 100 & \begin{tabular}{|l|l}
104 \\
\end{tabular} & \begin{tabular}{|l|}
108 \\
\end{tabular} \\
\hline 42 & 86 & 90 & 93 & 97 & 101 & 105 & \begin{tabular}{|l|}
109 \\
\end{tabular} \\
\hline
\end{tabular}

Table 2. Estimated biparietal diameter (BPD) in $\mathrm{mm}$ by gestational age (GA) for males and females, standard deviations (SD). ${ }^{\mathrm{a}} \mathrm{GA}$ expressed as completed gestational weeks, e.g. 12 weeks corresponds to $12+0$ weeks or 84 gestational days.

$$
\begin{gathered}
E(Z i)=8.48+\left[-14.36 \mathrm{GA}_{\mathrm{i}}^{-0.5}\right]+\left[-0.0002 \mathrm{GA}_{\mathrm{i}}^{2}\right] \\
\operatorname{Var}(\mathrm{Zi})=0.02+\left[0.25 \mathrm{GA}_{\mathrm{i}}^{-1}\right]+\left[-0.13 \mathrm{GA}_{\mathrm{i}}^{-0.5}\right]+\left[-8.24 \mathrm{e}-06 \mathrm{GA}_{\mathrm{i}}^{2}\right]+\left[0.00003 \mathrm{GA}_{\mathrm{i}}^{-0.5} \mathrm{GA}_{\mathrm{i}}^{2}\right]+\left[1.43 \mathrm{e}-09 \mathrm{GA}_{\mathrm{i}}^{4}\right]
\end{gathered}
$$

Table 6 shows the median and variance for estimated MAD by GA in SD, and Table 7 MAD by GA in percentiles. Figure $2 \mathrm{c}$ shows the raw data with fitted percentiles for estimated MAD by GA.

Mean and variance equation for MAD in males and females:

$$
E(Z i)=6.71+\left[-43.56 \mathrm{GA}_{\mathrm{i}}^{-2}\right]+\left[-12.17 \mathrm{GA}_{\mathrm{i}}^{-0.5}\right]
$$

$\operatorname{Var}(\mathrm{Zi})=0.04+\left[627.53 \mathrm{GA}_{\mathrm{i}}^{-4}\right]+\left[9.06 \mathrm{GA}_{\mathrm{i}}^{-2}\right]+\left[-0.50 \mathrm{GA}_{\mathrm{i}}^{-0.5}\right]+\left[-56.88 \mathrm{GA}_{\mathrm{i}}^{-2} \mathrm{GA}_{\mathrm{i}}^{-0.5}\right]+\left[1.48 \mathrm{GA}_{\mathrm{i}}^{-1}\right]$

Table 8 shows the median and variance for estimated AC by GA in SD, and Table 9 AC by GA in percentiles. Figure $2 \mathrm{~d}$ shows the raw data with fitted percentiles for estimated AC by GA.

Mean and variance equation for $\mathrm{AC}$ in males and females:

$$
E\left(Z_{\mathrm{i}}\right)=7.80+\left[-50.05 \mathrm{GA}_{\mathrm{i}}^{-2}\right]+\left[-11.80 \mathrm{GA}_{\mathrm{i}}^{-0.5}\right]
$$

$\operatorname{Var}\left(Z_{\mathrm{i}}\right)=0.04+\left[470.55 \mathrm{GA}_{\mathrm{i}}^{-4}\right]+\left[6.86 \mathrm{GA}_{\mathrm{i}}^{-2}\right]+\left[-0.39 \mathrm{GA}_{\mathrm{i}}^{-0.5}\right]+\left[-42.80 \mathrm{GA}_{\mathrm{i}}^{-2} \mathrm{GA}_{\mathrm{i}}^{-0.5}\right]+\left[1.15 \mathrm{GA}_{\mathrm{i}}^{-1}\right]$ 


\begin{tabular}{|c|c|c|c|c|c|c|c|c|c|}
\hline GA (weeks ${ }^{\mathrm{a}}$ ) & 2.5th & 5th & 10th & 25th & Median & 75th & 90th & 95th & 97.5th \\
\hline 12 & 19 & 19 & 20 & 20 & 20 & 21 & 21 & 21 & 21 \\
\hline 13 & 22 & 23 & 23 & 23 & 23 & 24 & 24 & 24 & 24 \\
\hline 14 & 25 & 26 & 26 & 26 & 27 & 27 & 28 & 28 & 28 \\
\hline 15 & 29 & 29 & 29 & 30 & 30 & 31 & 31 & 31 & 32 \\
\hline 16 & 32 & 32 & 32 & 33 & 34 & 34 & 35 & 35 & 35 \\
\hline 17 & 35 & 35 & 36 & 36 & 37 & 38 & 38 & 39 & 39 \\
\hline 18 & 38 & 39 & 39 & 40 & 41 & 41 & 42 & 43 & 43 \\
\hline 19 & 41 & 42 & 42 & 43 & 44 & 45 & 46 & 46 & 47 \\
\hline 20 & 45 & 45 & 46 & 46 & 48 & 49 & 50 & 50 & 51 \\
\hline 21 & 48 & 48 & 49 & 50 & 51 & 52 & 53 & 54 & 55 \\
\hline 22 & 51 & 51 & 52 & 53 & 54 & 56 & 57 & 58 & 58 \\
\hline 23 & 54 & 54 & 55 & 56 & 58 & 59 & 60 & 61 & 62 \\
\hline 24 & 57 & 57 & 58 & 59 & 61 & 62 & 64 & 65 & 65 \\
\hline 25 & 60 & 60 & 61 & 62 & 64 & 66 & 67 & 68 & 69 \\
\hline 26 & 62 & 63 & 64 & 65 & 67 & 69 & 70 & 71 & 72 \\
\hline 27 & 65 & 66 & 67 & 68 & 70 & 72 & 73 & 74 & 75 \\
\hline 28 & 68 & 68 & 69 & 71 & 73 & 75 & 76 & 77 & 78 \\
\hline 29 & 70 & 71 & 72 & 73 & 75 & 77 & 79 & 80 & 81 \\
\hline 30 & 72 & 73 & 74 & 76 & 78 & 80 & 82 & 83 & 84 \\
\hline 31 & 75 & 75 & 77 & 78 & 80 & 82 & 84 & 85 & 86 \\
\hline 32 & 77 & 78 & 79 & 80 & 82 & 85 & 86 & 88 & 89 \\
\hline 33 & 79 & 80 & 81 & 83 & 85 & 87 & 89 & 90 & 91 \\
\hline 34 & 81 & 81 & 83 & 84 & 87 & 89 & 91 & 92 & 93 \\
\hline 35 & 82 & 83 & 84 & 86 & 88 & 91 & 93 & 94 & 95 \\
\hline 36 & 84 & 85 & 86 & 88 & 90 & 92 & 94 & 96 & \begin{tabular}{|l|}
97 \\
\end{tabular} \\
\hline 37 & 85 & 86 & 87 & 89 & 92 & 94 & 96 & 97 & 98 \\
\hline 38 & 86 & 87 & 89 & 91 & 93 & 95 & 97 & 99 & 100 \\
\hline 39 & 87 & 89 & 90 & 92 & 94 & 97 & 99 & 100 & 101 \\
\hline 40 & 88 & 89 & 91 & 93 & 95 & 98 & 100 & 101 & \begin{tabular}{|l|}
103 \\
\end{tabular} \\
\hline 41 & 89 & 90 & 92 & 94 & 96 & 99 & 101 & 103 & 104 \\
\hline 42 & 90 & 91 & 92 & 95 & \begin{tabular}{|l|}
97 \\
\end{tabular} & 100 & 102 & 104 & 105 \\
\hline
\end{tabular}

Table 3. Estimated biparietal diameter (BPD) in mm by gestational age (GA) for males and females, percentiles. ${ }^{\mathrm{a}} \mathrm{GA}$ expressed as completed gestational weeks, e.g. 12 weeks corresponds to $12+0$ weeks or 84 gestational days.

Table 10 shows the median and variance for estimated FL by GA in SD, and Table 11 FL by GA in percentiles. Figure 2e shows the raw data with fitted percentiles for estimated FL by GA.

Mean and variance equation for FL in males and females:

$$
E\left(Z_{\mathrm{i}}\right)=4.11+\left[-344.24 \mathrm{GA}_{\mathrm{i}}^{-2}\right]+\left[0.01 \mathrm{GA}_{\mathrm{i}}^{1}\right]
$$

$$
\operatorname{Var}\left(Z_{\mathrm{i}}\right)=0.01+\left[584.71 \mathrm{GA}_{\mathrm{i}}^{-4}\right]+\left[-4.46 \mathrm{GA}_{\mathrm{i}}^{-2}\right]+\left[-0.0004 \mathrm{GA}_{\mathrm{i}}^{1}\right]+\left[0.10 \mathrm{GA}_{\mathrm{i}}^{-2} \mathrm{GA}_{\mathrm{i}}^{1}\right]+\left[4.83 \mathrm{e}-06 \mathrm{GA}_{\mathrm{i}}^{2}\right]
$$

Supplementary Tables 1-5 show the median and variance of the different biometric measurements (BPD, $\mathrm{HC}, \mathrm{MAD}, \mathrm{AC}$ and FL) for each gestational week for males and females separately. Supplementary Tables 6-10 show the median and variance of the different biometric measurements for each gestational day. The variance is expressed in standard deviations $(+3 \mathrm{SD},+2 \mathrm{SD},+1 \mathrm{SD}$, median, $-1 \mathrm{SD},-2 \mathrm{SD}$ and $-3 \mathrm{SD})$ and in percentiles (2.5th, 5th, 10th, 25th, median, 75th, 90th, 95th and 97.5th). Moreover, all supplementary tables enclose the full equations of mean and variance for each biometric measurement.

The sensitivity analysis of women with BMI 18.5 to $29.9 \mathrm{~kg} / \mathrm{m}^{2}$ showed no statistically significant differences between the reference ranges in the complete study population and the subset of women where underweight and obese women were excluded ( $\mathrm{p}=0.9906$ to 0.999 ). Supplementary Tables $11-15$ show the median and variance of 

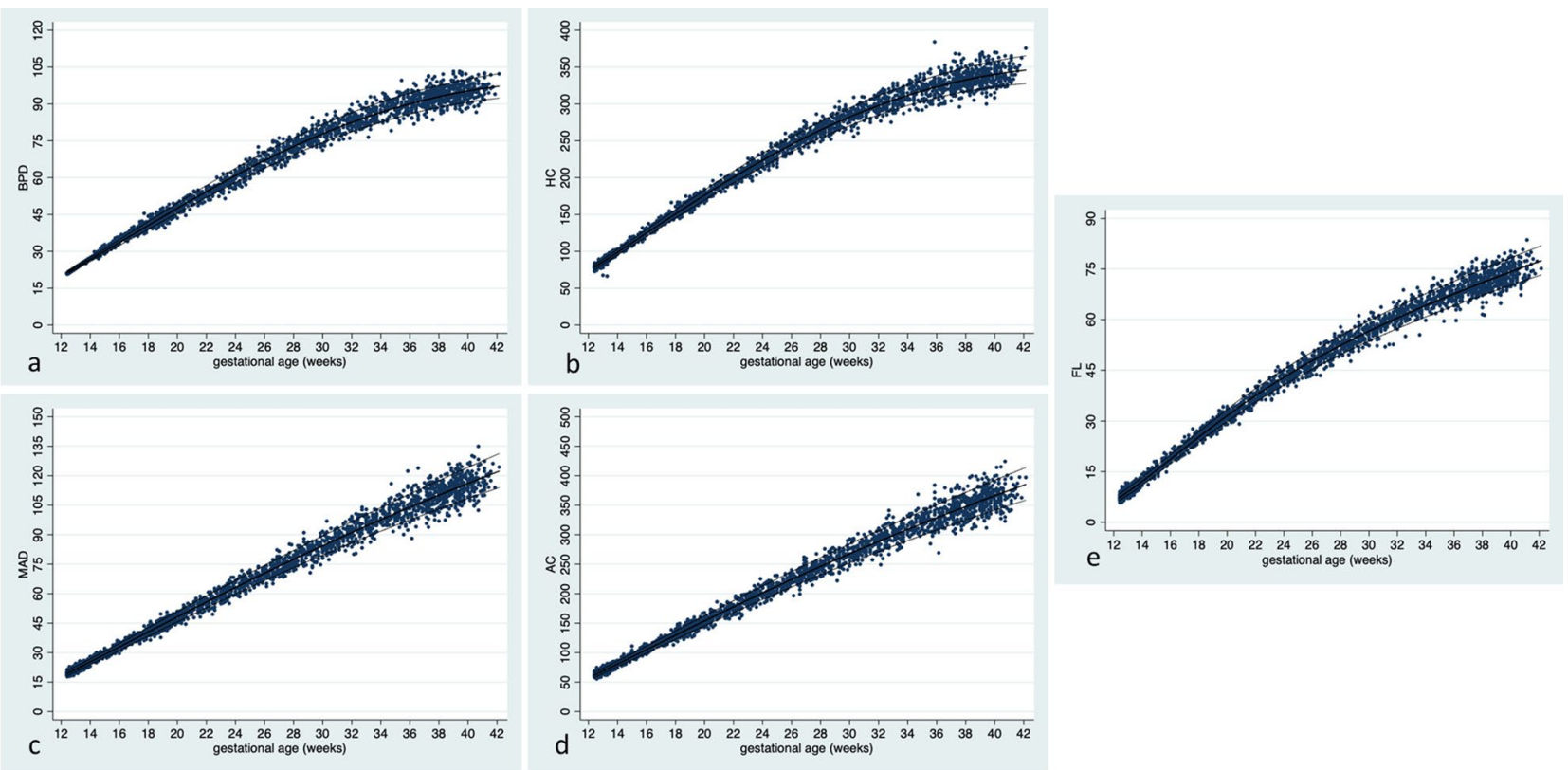

Figure 2. Raw data with fitted percentiles $(10,50,90)$ for each estimated biometrical measurement in $\mathrm{mm}$ by gestational age (GA). (a) Shows biparietal diameter (BPD) by GA $(\mathrm{n}=2586)$, (b) shows head circumference (HC) by GA ( $\mathrm{n}=2571)$, (c) shows mean abdominal diameter (MAD) by GA $(\mathrm{n}=2585)$, (d) shows abdominal circumference $(A C)$ by GA $(n=2561)$ and $(\mathbf{e})$ shows femur length $(F L)$ by GA $(n=2584)$.

the different biometric measurements for each gestational week in the subset of women with BMI 18.5 to $29.9 \mathrm{~kg} /$ $\mathrm{m}^{2}$. The variance is expressed in standard deviations $(+3 \mathrm{SD},+2 \mathrm{SD},+1 \mathrm{SD}$, median, $-1 \mathrm{SD},-2 \mathrm{SD}$ and $-3 \mathrm{SD})$ and in percentiles $(2.5 \mathrm{th}, 5 \mathrm{th}, 10 \mathrm{th}, 25 \mathrm{th}$, median, $75 \mathrm{th}$, 90th, 95th and $97.5 \mathrm{th})$. Moreover, the supplementary tables enclose the full equations of mean and variance for each biometric measurement.

The GA at examination of the five study subjects included in the reproducibility study varied from $13+3$ to $41+1$ gestational weeks. The linear mixed effects model showed overall non-significant inter-observer variation for all five biometric measurements, with $\mathrm{p}=0.162$ for $\mathrm{BPD}, \mathrm{p}=0.124$ for $\mathrm{HC}, \mathrm{p}=0.213$ for $\mathrm{FL}, \mathrm{p}=0.087$ for MAD and $p=0.166$ for AC. The two-way mixed effects model of average measures and absolute agreement showed a very high ICC, with highly consistent measurements for all five biometric measurements; ICC for BPD $=1.000$, for $\mathrm{HC}=1.000$, for $\mathrm{FL}=1.000$, for $\mathrm{MAD}=0.999$ and for $\mathrm{AC}=0.979$.

\section{Discussion}

In this cohort of prospectively enrolled, healthy women with low risk of aberrant fetal growth, we have constructed new Swedish reference ranges for normal size and growth of the fetal head, abdomen and femur. We have provided charts for five biometric measurements; BPD, HC, MAD, AC and FL, from gestational week 12 to 42.

Over the years, a large number of studies have presented regional and international charts for fetal size and growth. There is a large variability in study design and statistical modelling methods, as well as in reported percentiles $^{3,4,18}$. The aim of a fetal growth chart is to describe how fetuses should grow under optimal conditions ${ }^{3}$. Hence, in concordance with large international studies of fetal size and growth, the present study has only included women with low risk of aberrant fetal growth ${ }^{5,6}$.

Reliable and population-representative size and growth charts are important in order to correctly evaluate both fetal size and growth, the latter as serial measurements. Altman and Chitty highlight differences in estimating size and growth, and how this affects the choice of appropriate study design ${ }^{18}$. A cross-sectional design is recommended for evaluating size, with a single measurement on each study subject. Longitudinal studies, on the other hand, comprise repeated measurements of each study subject. Compared with cross-sectional studies, longitudinal studies often use smaller study samples with measurements that are not independent of each other. Unless the repeated measurements are properly addressed, the variation may be underestimated using a longitudinal design. Since the publication of the intrauterine growth charts constructed by Maršál et al. in ${ }^{12}$, which are presently used in Sweden, statistical methods have been developed and used that take both repeated measurements and increased variation with GA into account. These methods permit the use of a longitudinal design to produce growth charts of size as well as growth intended for clinical practice ${ }^{4,18}$. A strength of our study is the prospective longitudinal design and the use of modern statistical modelling methods. Hence, the growth charts can be used to evaluate ultrasonically derived fetal biometry, both regarding size and growth. However, these growth charts are not intended for dating of pregnancies, as dating standards require different statistical analyses ${ }^{19}$. We recommend the use of dating charts that are designed solely for that purpose. 


\begin{tabular}{|c|c|c|c|c|c|c|c|}
\hline GA (weeks ${ }^{\mathrm{a}}$ ) & $-3 \mathrm{SD}$ & $-2 S D$ & -1 SD & Median & $+1 \mathrm{SD}$ & $+2 \mathrm{SD}$ & $+3 \mathrm{SD}$ \\
\hline 12 & 66 & 69 & 71 & 74 & 76 & 79 & 82 \\
\hline 13 & 78 & 81 & 83 & 86 & 89 & 92 & 95 \\
\hline 14 & 90 & 93 & 96 & 99 & 102 & 105 & 108 \\
\hline 15 & 102 & 105 & 108 & 112 & 115 & 118 & 122 \\
\hline 16 & 114 & 118 & 121 & 125 & 128 & 132 & 136 \\
\hline 17 & 126 & 130 & 134 & 138 & 142 & 146 & 150 \\
\hline 18 & 138 & 142 & 146 & 151 & 155 & 160 & 164 \\
\hline 19 & 150 & 154 & 159 & 164 & 168 & 173 & 179 \\
\hline 20 & 161 & 166 & 171 & 176 & 181 & 187 & 192 \\
\hline 21 & 172 & 178 & 183 & 188 & 194 & 200 & 206 \\
\hline 22 & 183 & 189 & 195 & 201 & 207 & 213 & 220 \\
\hline 23 & 194 & 200 & 206 & 212 & 219 & 226 & 233 \\
\hline 24 & 204 & 210 & 217 & 224 & 231 & 238 & 245 \\
\hline 25 & 213 & 220 & 227 & 234 & 242 & 250 & 258 \\
\hline 26 & 223 & 230 & 237 & 245 & 253 & 261 & 270 \\
\hline 27 & 231 & 239 & 247 & 255 & 263 & 272 & 281 \\
\hline 28 & 240 & 248 & 256 & 265 & 273 & 282 & 292 \\
\hline 29 & 248 & 256 & 265 & 274 & 283 & 292 & 302 \\
\hline 30 & 255 & 264 & 273 & 282 & 292 & 302 & 312 \\
\hline 31 & 262 & 271 & 281 & 290 & 300 & 311 & 321 \\
\hline 32 & 269 & 278 & 288 & 298 & 308 & 319 & 330 \\
\hline 33 & 275 & 285 & 295 & 305 & 316 & 327 & 338 \\
\hline 34 & 280 & 290 & 301 & 312 & 323 & 334 & 346 \\
\hline 35 & 285 & 296 & 306 & 318 & 329 & 341 & 353 \\
\hline 36 & 290 & 301 & 312 & 323 & 335 & \begin{tabular}{|l|l}
347 \\
\end{tabular} & 360 \\
\hline 37 & 294 & 305 & 316 & 328 & 340 & 353 & 367 \\
\hline \begin{tabular}{|l|}
38 \\
\end{tabular} & 297 & \begin{tabular}{|l|}
308 \\
\end{tabular} & 320 & 333 & 345 & 359 & 373 \\
\hline \begin{tabular}{|l|}
39 \\
\end{tabular} & 300 & 311 & 324 & \begin{tabular}{|l|l}
337 \\
\end{tabular} & 350 & 364 & 378 \\
\hline 40 & 302 & 314 & 327 & 340 & 354 & 368 & 383 \\
\hline \begin{tabular}{|l|}
41 \\
\end{tabular} & 303 & 316 & 329 & 343 & \begin{tabular}{|l}
357 \\
\end{tabular} & 372 & \begin{tabular}{|l|}
388 \\
\end{tabular} \\
\hline 42 & 304 & 318 & 331 & 346 & 361 & 376 & 392 \\
\hline
\end{tabular}

Table 4. Estimated head circumference (HC) in mm by gestational age (GA) for males and females, standard deviations (SD). ${ }^{a} \mathrm{GA}$ expressed as completed gestational weeks, e.g. 12 weeks corresponds to $12+0$ weeks or 84 gestational days.

Another strength of our study is the relatively large cohort of healthy women with low-risk pregnancies recruited specifically for this study with an even spread of the examinations across the included GAs. In order to increase the reproducibility and decrease the measurement error, a limited number of experienced sonographers conducted the ultrasound scans following the biometric measurement recommendations that are in use in Sweden. The use of triplicate measurements of each biometric assessment at each ultrasound scan further reduces measurement error. The reproducibility study showed a low grade of inter-observer variability. However, the low number of study subjects is a limitation. Accordingly, the reliability of the reproducibility study cannot be assessed as high. Lastly, strict criteria for exclusion due to increased risk of aberrant growth have been applied throughout the study.

A valid estimation of GA is considered crucial for developing reliable growth reference ranges ${ }^{3}$. The used method with regular menstrual cycles where estimated date of delivery (EDD) according to last menstrual period is consistent with first trimester ultrasound dating provides a reliable dating method ${ }^{3,420-22}$. The median discrepancy of 0 days in our study indicates concordant dating between EDD according to BPD and EDD according to last menstrual period. The mean dating discrepancy was larger for girls than for boys. The dating discrepancy is in line with the findings of earlier studies that have examined discrepancy in dating using last menstrual period and ultrasound ${ }^{23,24}$. We used BPD in gestational week $12+3-13+6$ to date the pregnancies. Swedish as well as international guidelines recommend dating with ultrasound during the first trimester, as this appears to be the most reliable method for pregnancy dating ${ }^{14,25}$. The Swedish guidelines recommend the use of crown rump length $(\mathrm{CRL})$ in early pregnancy, and BPD from $21 \mathrm{~mm}$ (corresponding to week $12+3$ ). Adherance to the recommendations of using CRL for dating in early pregnancy is however low in Sweden ${ }^{26}$. Since many Swedish 


\begin{tabular}{|c|c|c|c|c|c|c|c|c|c|}
\hline GA (weeks ${ }^{a}$ ) & 2.5th & 5th & 10th & 25th & Median & 75th & 90th & 95th & 97.5th \\
\hline 12 & 69 & 69 & 70 & 72 & 74 & 75 & 77 & 78 & 79 \\
\hline 13 & 81 & 82 & 83 & 84 & 86 & 88 & 90 & 91 & 92 \\
\hline 14 & 93 & 94 & 95 & 97 & 99 & 101 & 103 & 104 & 105 \\
\hline 15 & 105 & 106 & 108 & 110 & 112 & 114 & 116 & 117 & 118 \\
\hline 16 & 118 & 119 & 120 & 122 & 125 & 127 & 129 & 131 & 132 \\
\hline 17 & 130 & 131 & 133 & 135 & 138 & 140 & 143 & 144 & 146 \\
\hline 18 & 142 & 144 & 145 & 148 & 151 & 154 & 156 & 158 & 160 \\
\hline 19 & 154 & 156 & 158 & 160 & 164 & 167 & 170 & 172 & 173 \\
\hline 20 & 166 & 168 & 170 & 173 & 176 & 180 & 183 & 185 & 187 \\
\hline 21 & 178 & 179 & 181 & 185 & 188 & 192 & 196 & 198 & 200 \\
\hline 22 & 189 & 191 & 193 & 196 & 201 & 205 & 208 & 211 & 213 \\
\hline 23 & 200 & 202 & 204 & 208 & 212 & 217 & 221 & 223 & 225 \\
\hline 24 & 210 & 212 & 215 & 219 & 224 & 228 & 233 & 235 & 238 \\
\hline 25 & 220 & 223 & 225 & 230 & 234 & 239 & 244 & 247 & 249 \\
\hline 26 & 230 & 232 & 235 & 240 & 245 & 250 & 255 & 258 & 261 \\
\hline 27 & 239 & 242 & 245 & 250 & 255 & 261 & 266 & 269 & 272 \\
\hline 28 & 248 & 251 & 254 & 259 & 265 & 270 & 276 & 279 & 282 \\
\hline 29 & 257 & 259 & 262 & 268 & 274 & 280 & 285 & 289 & 292 \\
\hline 30 & 264 & 267 & 270 & 276 & 282 & 289 & 295 & 298 & 301 \\
\hline 31 & 272 & 275 & 278 & 284 & 290 & 297 & 303 & 307 & 310 \\
\hline 32 & 279 & 282 & 285 & 291 & 298 & 305 & 311 & 315 & 318 \\
\hline 33 & 285 & 288 & 292 & 298 & 305 & 312 & 319 & 323 & 326 \\
\hline 34 & 291 & 294 & 298 & 304 & 312 & 319 & 326 & 330 & 334 \\
\hline 35 & 296 & 300 & 303 & 310 & 318 & 325 & 332 & 337 & 341 \\
\hline 36 & 301 & 304 & \begin{tabular}{|l|}
308 \\
\end{tabular} & 315 & 323 & 331 & 338 & 343 & 347 \\
\hline 37 & 305 & 309 & 313 & 320 & 328 & 336 & 344 & 349 & 353 \\
\hline 38 & 309 & 313 & 317 & 324 & 333 & 341 & 349 & 354 & 358 \\
\hline 39 & 312 & 316 & 320 & 328 & 337 & 346 & 354 & 359 & 363 \\
\hline 40 & 315 & 319 & 323 & 331 & 340 & 349 & 358 & 363 & 368 \\
\hline 41 & 317 & 321 & 325 & 334 & 343 & 353 & 362 & 367 & 372 \\
\hline 42 & 318 & 322 & 327 & 336 & 346 & 356 & 365 & 371 & 376 \\
\hline
\end{tabular}

Table 5. Estimated head circumference $(\mathrm{HC})$ in $\mathrm{mm}$ by gestational age (GA) for males and females, percentiles. a GA expressed as completed gestational weeks, e.g. 12 weeks corresponds to $12+0$ weeks or 84 gestational days.

sonographers are not experienced in measuring CRL, we chose to date all pregnancies with BPD in order to avoid different dating methods. Further, the equation used for dating with BPD was derived with CRL as reference for "true" GA, and later the equation was validated as well performing with low systematic and random error ${ }^{27,28}$. However, first trimester dating with BPD predicts the GA and duration of pregnancy equally well as CRL, and the choice of future dating method should therefore not affect the applicability of our growth charts ${ }^{27,29}$. Variations in early growth might have an impact on the estimated GA when first trimester ultrasound dating is used rather than last menstrual period. This implies that there is a risk that a systematic bias caused by measurement error is introduced. The potential effect of inaccurate GA assessment due to natural variation in fetal growth should however be small, as the dating discrepancy was very small.

A limitation of the study is the predominance $(92.1 \%)$ of women born in Sweden or another Nordic country. This figure is high compared with the Swedish pregnant population, where $69.5 \%$ of all women giving birth in Sweden in 2018 were born in a Nordic country ${ }^{13}$. Some selection bias was unavoidable, as the written information to potential study subjects that was handed out during the recruitment process was solely available in Swedish, English and Arabic. Efforts were made to recruit women of various ethnicities and social backgrounds, by recruiting women in primary care units with a high rate of immigrants as well as in units with mainly Swedish born women.

In order to achieve a study population representative to the Swedish pregnant population, women of low as well as high BMI were included in the cohort, despite the potential effect of abnormal BMI on intrauterine growth. Since only healthy women were included, the risk of poor intrauterine growth due to malnutrition should be low. Even though the median BMI was normal, the upper interquartile range included women with overweight, indicating that a significant part of the study population were overweight. Women with obesity were 


\begin{tabular}{|c|c|c|c|c|c|c|c|}
\hline GA (weeks ${ }^{a}$ ) & $-3 \mathrm{SD}$ & $-2 \mathrm{SD}$ & -1 SD & Median & $+1 \mathrm{SD}$ & $+2 \mathrm{SD}$ & $+3 \mathrm{SD}$ \\
\hline 12 & 15 & 16 & 17 & 18 & 19 & 20 & 21 \\
\hline 13 & 19 & 20 & 21 & 22 & 23 & 24 & 25 \\
\hline 14 & 22 & 23 & 24 & 25 & 26 & 28 & 29 \\
\hline 15 & 26 & 27 & 28 & 29 & 30 & 32 & 33 \\
\hline 16 & 29 & 30 & 32 & 33 & 34 & 36 & 37 \\
\hline 17 & 32 & 34 & 35 & 37 & 38 & 40 & 42 \\
\hline 18 & 36 & 37 & 39 & 41 & 42 & 44 & 46 \\
\hline 19 & 39 & 41 & 43 & 44 & 46 & 48 & 50 \\
\hline 20 & 42 & 44 & 46 & 48 & 50 & 52 & 55 \\
\hline 21 & 46 & 48 & 50 & 52 & 54 & 57 & 59 \\
\hline 22 & 49 & 51 & 53 & 56 & 58 & 61 & 63 \\
\hline 23 & 52 & 55 & 57 & 59 & 62 & 65 & 68 \\
\hline 24 & 56 & 58 & 61 & 63 & 66 & 69 & 72 \\
\hline 25 & 59 & 61 & 64 & 67 & 70 & 73 & 76 \\
\hline 26 & 62 & 65 & 67 & 70 & 73 & 77 & 80 \\
\hline 27 & 65 & 68 & 71 & 74 & 77 & 81 & 84 \\
\hline 28 & 68 & 71 & 74 & 77 & 81 & 85 & 88 \\
\hline 29 & 71 & 74 & 77 & 81 & 85 & 88 & 92 \\
\hline 30 & 74 & 77 & 81 & 84 & 88 & 92 & 97 \\
\hline 31 & 77 & 80 & 84 & 88 & 92 & 96 & 101 \\
\hline 32 & 79 & 83 & 87 & 91 & 95 & 100 & 105 \\
\hline 33 & 82 & 86 & 90 & 94 & 99 & 104 & 109 \\
\hline 34 & 85 & 89 & 93 & 98 & 102 & 107 & 113 \\
\hline 35 & 87 & 91 & 96 & 101 & 106 & 111 & 117 \\
\hline 36 & 90 & 94 & 99 & 104 & 109 & 115 & 121 \\
\hline 37 & 92 & 97 & 102 & 107 & 113 & 118 & 124 \\
\hline 38 & 94 & 99 & 105 & 110 & 116 & 122 & 128 \\
\hline 39 & 97 & 102 & 107 & 113 & 119 & 126 & 132 \\
\hline 40 & 99 & 104 & 110 & 116 & 122 & 129 & 136 \\
\hline 41 & 101 & 107 & 113 & 119 & 126 & 133 & 140 \\
\hline 42 & 103 & 109 & 115 & 122 & 129 & 136 & 144 \\
\hline
\end{tabular}

Table 6. Estimated mean abdominal diameter (MAD) in mm by gestational age (GA) for males and females, standard deviations (SD). ${ }^{\mathrm{a}} \mathrm{GA}$ expressed as completed gestational weeks, e.g. 12 weeks corresponds to $12+0$ weeks or 84 gestational days.

not only screened with repeated random plasma glucose, but also with oral glucose tolerance test for gestational diabetes. All women who developed gestational diabetes were excluded, and solely women with normal plasma glucose and glucose tolerance fulfilled the study. It cannot be ruled out that increased fetal growth due to other factors than gestational diabetes in obese women might affect the results towards an overestimation of normal fetal size. In the sensitivity analysis, where women with BMI 18.5 to $29.9 \mathrm{~kg} / \mathrm{m}^{2}$ were compared with the complete study population, only small differences were observed between the groups for all biometric measurements. These differences should not be of any clinical significance, and neither were there any statistically significant differences between the reference ranges if all women were included or not. Hence, including the subjects with extreme BMI values should not bias the results. Moreover, the aim of the study was to provide reference ranges in a study population of healthy women representative to the Swedish pregnant population. Maternal age and BMI in the study population were similar to the mean age (30.4 years) and BMI $\left(25.2 \mathrm{~kg} / \mathrm{m}^{2}\right)$ of pregnant women in Sweden $2017^{13}$. Hence, the results of the complete study population can be regarded as generalizable for estimation of fetal size and growth in the current Swedish pregnant population.

Compared with the growth charts presently used in Sweden, our new reference ranges are derived from an almost seven times larger study population ${ }^{12}$. Moreover, the study population in Maršál's study comprises $24 \%$ smokers. Considering the potential growth retarding effect of maternal smoking, their study population does not represent a low-risk population with expected normal fetal growth ${ }^{30,31}$. Methodological considerations, such as the nowadays outdated cross-sectional analytic methods of a longitudinal study in the Maršál study, and changes in the Swedish pregnant population, motivates a change into updated reference ranges for fetal size and growth. Moreover, the corresponding Norwegian growth charts, which are based on a methodology similar to ours, are 


\begin{tabular}{|c|c|c|c|c|c|c|c|c|c|}
\hline GA (weeks ${ }^{a}$ ) & 2.5th & 5th & 10th & 25th & Median & 75th & 90th & 95th & 97.5th \\
\hline 12 & 16 & 16 & 17 & 17 & 18 & 19 & 19 & 20 & 20 \\
\hline 13 & 20 & 20 & 20 & 21 & 22 & 22 & 23 & 23 & 24 \\
\hline 14 & 23 & 23 & 24 & 25 & 25 & 26 & 27 & 27 & 28 \\
\hline 15 & 27 & 27 & 27 & 28 & 29 & 30 & 31 & 31 & 32 \\
\hline 16 & 30 & 31 & 31 & 32 & 33 & 34 & 35 & 35 & 36 \\
\hline 17 & 34 & 34 & 35 & 36 & 37 & 38 & 39 & 39 & 40 \\
\hline 18 & 37 & 38 & 38 & 39 & 41 & 42 & 43 & 43 & 44 \\
\hline 19 & 41 & 41 & 42 & 43 & 44 & 46 & 47 & 48 & 48 \\
\hline 20 & 44 & 45 & 46 & 47 & 48 & 50 & 51 & 52 & 52 \\
\hline 21 & 48 & 48 & 49 & 51 & 52 & 53 & 55 & 56 & 56 \\
\hline 22 & 51 & 52 & 53 & 54 & 56 & 57 & 59 & 60 & 61 \\
\hline 23 & 55 & 55 & 56 & 58 & 59 & 61 & 63 & 64 & 65 \\
\hline 24 & 58 & 59 & 60 & 61 & 63 & 65 & 67 & 68 & 69 \\
\hline 25 & 61 & 62 & 63 & 65 & 67 & 69 & 71 & 72 & 73 \\
\hline 26 & 65 & 66 & 67 & 68 & 70 & 72 & 74 & 76 & 77 \\
\hline 27 & 68 & 69 & 70 & 72 & 74 & 76 & 78 & 79 & 81 \\
\hline 28 & 71 & 72 & 73 & 75 & 77 & 80 & 82 & 83 & 84 \\
\hline 29 & 74 & 75 & 76 & 79 & 81 & 83 & 86 & 87 & 88 \\
\hline 30 & 77 & 78 & 80 & 82 & 84 & 87 & 89 & 91 & 92 \\
\hline 31 & 80 & 81 & 83 & 85 & 88 & 90 & 93 & 95 & 96 \\
\hline 32 & 83 & 84 & 86 & 88 & 91 & 94 & 97 & 98 & 100 \\
\hline 33 & 86 & 87 & 89 & 91 & 94 & 97 & \begin{tabular}{|l|}
100 \\
\end{tabular} & 102 & 103 \\
\hline 34 & 89 & 90 & 92 & 94 & 98 & 101 & 104 & 106 & 107 \\
\hline 35 & 92 & 93 & 95 & 98 & 101 & 104 & 107 & 109 & 111 \\
\hline 36 & 94 & 96 & 98 & 101 & 104 & \begin{tabular}{|l|}
107 \\
\end{tabular} & 111 & 113 & 114 \\
\hline 37 & 97 & 98 & 100 & 103 & 107 & 111 & 114 & 116 & 118 \\
\hline 38 & 100 & \begin{tabular}{|l|}
101 \\
\end{tabular} & 103 & 106 & 110 & 114 & \begin{tabular}{|l|}
118 \\
\end{tabular} & 120 & 122 \\
\hline 39 & 102 & 104 & 106 & \begin{tabular}{|l|l|}
109 \\
\end{tabular} & 113 & 117 & 121 & 123 & 125 \\
\hline 40 & 105 & 106 & 108 & 112 & 116 & 120 & 124 & 127 & 129 \\
\hline 41 & \begin{tabular}{|l|}
107 \\
\end{tabular} & \begin{tabular}{|l|l|}
109 \\
\end{tabular} & 111 & 115 & 119 & 123 & 128 & 130 & 132 \\
\hline 42 & \begin{tabular}{|l|l|}
109 \\
\end{tabular} & 111 & 114 & 117 & 122 & 126 & 131 & 133 & 136 \\
\hline
\end{tabular}

Table 7. Estimated mean abdominal diameter (MAD) in $\mathrm{mm}$ by gestational age (GA) for males and females, percentiles. ${ }^{\mathrm{a}} \mathrm{GA}$ expressed as completed gestational weeks, e.g. 12 weeks corresponds to $12+0$ weeks or 84 gestational days.

not entirely applicable to the Swedish setting, partly due to differences in demographics and birthweights, but most importantly due to differences in recommendations for how to perform the ultrasonic BPD measurements. The Norwegian reference ranges for biometry are calculated using the calipers placed on the outer margins of both the proximal and the distal parietal bone ${ }^{16}$.

During the last few years, large international projects have produced growth standards intended for universal use, with the assumption that differences in fetal growth and birthweights are caused by suboptimal environment rather than inherent differences in the populations ${ }^{5,6,32}$. Others have found evidence supporting that physiological differences rather than pathology explain the differences in size and growth between populations ${ }^{8,33-35}$. Applying international standards would in such a case possibly misclassify a large proportion of fetuses as either SGA, AGA or $\mathrm{LGA}^{10}$. There is an ongoing debate concerning the need of national standards for fetal size and growth. It is interesting to note that even though the INTERGROWTH-21st project showed high degree of likeness between study sites, the WHO Multicentre Growth Reference Study reported significant differences in fetal growth in different settings $s^{5,6}$. Even though both studies are of high quality with large study populations, recent studies have presented evidence that questions the use of a single international standard that represents ideal growth in all populations $s^{8-10,35}$. Similar conclusions were drawn by the authors of the WHO study, who recommend that if international charts are used, their performance should be tested in the local setting to assess if adjustments are needed $^{5}$. Bearing these concerns in mind, we believe that there is a need for updated national reference ranges of fetal size and growth for everyday clinical practice. Moreover, further studies are needed to evaluate proper cutoffs for the updated reference ranges in order to identify fetuses with increased risk of adverse perinatal outcome. 


\begin{tabular}{|c|c|c|c|c|c|c|c|}
\hline GA (weeks ${ }^{\mathrm{a}}$ ) & $-3 \mathrm{SD}$ & $-2 S D$ & -1 SD & Median & $+1 \mathrm{SD}$ & $+2 \mathrm{SD}$ & $+3 \mathrm{SD}$ \\
\hline 12 & 48 & 51 & 54 & 57 & 60 & 64 & 67 \\
\hline 13 & 59 & 62 & 65 & 69 & 72 & 76 & 80 \\
\hline 14 & 70 & 74 & 77 & 81 & 84 & 88 & 93 \\
\hline 15 & 81 & 85 & 89 & 93 & 97 & 101 & 106 \\
\hline 16 & 92 & 96 & 100 & 105 & 110 & 115 & 120 \\
\hline 17 & 103 & 107 & 112 & 117 & 122 & 128 & 134 \\
\hline 18 & 114 & 119 & 124 & 129 & 135 & 141 & 147 \\
\hline 19 & 124 & 130 & 136 & 142 & 148 & 155 & 161 \\
\hline 20 & 135 & 141 & 147 & 154 & 161 & 168 & 175 \\
\hline 21 & 146 & 152 & 159 & 166 & 173 & 181 & 189 \\
\hline 22 & 156 & 163 & 170 & 178 & 186 & 194 & 203 \\
\hline 23 & 166 & 174 & 181 & 190 & 198 & 207 & 216 \\
\hline 24 & 176 & 184 & 192 & 201 & 210 & 220 & 230 \\
\hline 25 & 186 & 195 & 203 & 213 & 222 & 232 & 243 \\
\hline 26 & 196 & 205 & 214 & 224 & 234 & 245 & 256 \\
\hline 27 & 205 & 215 & 225 & 235 & 246 & 257 & 269 \\
\hline 28 & 215 & 225 & 235 & 246 & 258 & 270 & 282 \\
\hline 29 & 224 & 234 & 245 & 257 & 269 & 282 & 295 \\
\hline 30 & 233 & 244 & 255 & 268 & 280 & 294 & 308 \\
\hline 31 & 241 & 253 & 265 & 278 & 292 & 306 & 321 \\
\hline 32 & 250 & 262 & 275 & 289 & 303 & 318 & 333 \\
\hline 33 & \begin{tabular}{|l|}
258 \\
\end{tabular} & 271 & 285 & 299 & 314 & 329 & 346 \\
\hline 34 & 266 & 280 & 294 & 309 & 324 & 341 & 358 \\
\hline 35 & 274 & 288 & 303 & 319 & 335 & 352 & 370 \\
\hline 36 & 282 & \begin{tabular}{|l|l}
297 \\
\end{tabular} & 312 & 328 & 346 & 364 & 383 \\
\hline 37 & 290 & 305 & 321 & 338 & 356 & 375 & 395 \\
\hline 38 & 297 & 313 & 330 & 348 & 366 & 386 & \begin{tabular}{|l|l}
407 \\
\end{tabular} \\
\hline 39 & 304 & 321 & 338 & 357 & 376 & 397 & 419 \\
\hline 40 & 311 & 329 & 347 & 366 & 386 & 408 & 431 \\
\hline 41 & 318 & 336 & 355 & 375 & 396 & \begin{tabular}{|l|l}
419 \\
\end{tabular} & 442 \\
\hline 42 & 325 & 343 & 363 & 384 & \begin{tabular}{|l|l}
406 \\
\end{tabular} & \begin{tabular}{|l}
429 \\
\end{tabular} & 454 \\
\hline
\end{tabular}

Table 8. Estimated abdominal circumference (AC) in $\mathrm{mm}$ by gestational age (GA) for males and females, standard deviations (SD). ${ }^{\mathrm{a}} \mathrm{GA}$ expressed as completed gestational weeks, e.g. 12 weeks corresponds to $12+0$ weeks or 84 gestational days.

In conclusion, as regional differences in fetal size and growth seem to be of clinical importance, this prospective longitudinal study of normal fetal growth in a healthy Swedish population provides new national reference ranges for fetal size and growth from gestational week 12 to 42 .

Research involving human participants. The study was approved by the Regional Ethical Review Board in Uppsala (no. 2014/209 and 2014/209/2). All procedures involving human subjects were carried out in accordance with the ethical standards of the 1964 Helsinki declaration. All women participated voluntarily and gave their informed consent. Any pregnancy complication recognized during the study was reported to the routine obstetric care at each study site and managed according to clinical practice. 
\begin{tabular}{|l|l|l|l|l|l|l|l|l|l|}
\hline GA (weeks ${ }^{\mathrm{a}}$ ) & 2.5th & 5th & 10th & 25th & Median & 75th & 90th & 95th & 97.5th \\
\hline
\end{tabular}

\begin{tabular}{|c|c|c|c|c|c|c|c|c|c|}
\hline 12 & 51 & 52 & 53 & 55 & 57 & 59 & 61 & 63 & 64 \\
\hline 13 & 62 & 63 & 65 & 67 & 69 & 71 & 73 & 75 & 76 \\
\hline 14 & 74 & 75 & 76 & 78 & 81 & 83 & 86 & 87 & 88 \\
\hline 15 & 85 & 86 & 88 & 90 & 93 & 96 & 98 & 100 & 101 \\
\hline 16 & 96 & 98 & 99 & 102 & 105 & 108 & 111 & 113 & 114 \\
\hline 17 & 108 & 109 & 111 & 114 & 117 & 121 & 124 & 126 & 128 \\
\hline 18 & 119 & 121 & 122 & 126 & 129 & 133 & 137 & 139 & 141 \\
\hline 19 & 130 & 132 & 134 & 138 & 142 & 146 & 150 & 152 & 154 \\
\hline 20 & 141 & 143 & 145 & 149 & 154 & 158 & 163 & 165 & 167 \\
\hline 21 & 152 & 154 & 157 & 161 & 166 & 171 & 175 & 178 & 181 \\
\hline 22 & 163 & 165 & 168 & 173 & 178 & 183 & 188 & 191 & 194 \\
\hline 23 & 174 & 176 & 179 & 184 & 190 & 195 & 200 & 204 & 207 \\
\hline 24 & 184 & 187 & 190 & 195 & 201 & 207 & 213 & 216 & 219 \\
\hline 25 & 195 & 198 & 201 & 206 & 213 & 219 & 225 & 229 & 232 \\
\hline 26 & 205 & 208 & 211 & 217 & 224 & 231 & 237 & 241 & 245 \\
\hline 27 & 215 & 218 & 222 & 228 & 235 & 242 & 249 & 253 & 257 \\
\hline 28 & 225 & 228 & 232 & 239 & 246 & 254 & 261 & 265 & 269 \\
\hline 29 & 235 & 238 & 242 & 249 & 257 & 265 & 273 & 277 & 281 \\
\hline 30 & 244 & 248 & 252 & 259 & 268 & 276 & 284 & 289 & 293 \\
\hline 31 & 254 & 257 & 262 & 269 & 278 & 287 & 296 & 301 & 305 \\
\hline 32 & 263 & 267 & 271 & 279 & 289 & 298 & 307 & 312 & 317 \\
\hline 33 & 272 & 276 & 281 & 289 & 299 & 309 & 318 & 324 & 329 \\
\hline 34 & 280 & 285 & 290 & 299 & 309 & 319 & 329 & 335 & 340 \\
\hline 35 & 289 & 293 & 299 & 308 & 319 & 330 & 340 & 346 & 352 \\
\hline 36 & 297 & 302 & 308 & 317 & 328 & 340 & 351 & 357 & 363 \\
\hline 37 & 306 & 311 & 316 & 327 & 338 & 350 & 361 & 368 & 374 \\
\hline 38 & 314 & 319 & 325 & 335 & 348 & 360 & 372 & 379 & 385 \\
\hline 39 & 321 & 327 & 333 & 344 & 357 & 370 & 382 & 390 & 396 \\
\hline 40 & 329 & 335 & 342 & 353 & 366 & 380 & 392 & 400 & 407 \\
\hline 41 & 337 & 343 & 350 & 361 & 375 & 389 & 402 & 411 & 418 \\
\hline 42 & 344 & 350 & 358 & 370 & 384 & 399 & 412 & 421 & 428 \\
\hline
\end{tabular}

Table 9. Estimated abdominal circumference (AC) in mm by gestational age (GA) for males and females, percentiles. ${ }^{\text {a }} \mathrm{GA}$ expressed as completed gestational weeks, e.g. 12 weeks corresponds to $12+0$ weeks or 84 gestational days. 
\begin{tabular}{|l|l|l|l|l|l|l|l|}
\hline GA (weeks $^{\mathrm{a}}$ ) & $-3 \mathrm{SD}$ & $-\mathbf{2} \mathrm{SD}$ & $-1 \mathrm{SD}$ & Median & $+1 \mathrm{SD}$ & $+2 \mathrm{SD}$ & $+3 \mathrm{SD}$ \\
\hline
\end{tabular}

\begin{tabular}{|c|c|c|c|c|c|c|c|}
\hline 12 & 5 & 5 & 6 & 6 & 7 & 8 & 9 \\
\hline 13 & 7 & 8 & 8 & 9 & \begin{tabular}{|l|l}
10 \\
\end{tabular} & 11 & 12 \\
\hline 14 & 10 & 10 & 11 & 12 & 13 & 14 & 15 \\
\hline 15 & 13 & 14 & 14 & 15 & 16 & \begin{tabular}{|l}
17 \\
\end{tabular} & 19 \\
\hline 16 & 16 & 17 & 18 & 19 & 20 & 21 & 22 \\
\hline 17 & 19 & 20 & 21 & 22 & 23 & 24 & 26 \\
\hline 18 & 22 & 23 & 24 & 25 & 27 & 28 & 29 \\
\hline 19 & 25 & 26 & 27 & 28 & 30 & 31 & 33 \\
\hline 20 & 28 & 29 & 30 & 32 & 33 & 34 & 36 \\
\hline 21 & 30 & 32 & 33 & 35 & 36 & 38 & 39 \\
\hline 22 & 33 & 34 & 36 & \begin{tabular}{|l}
37 \\
\end{tabular} & 39 & 41 & 43 \\
\hline 23 & 35 & 37 & 39 & 40 & 42 & 44 & 46 \\
\hline 24 & 38 & 39 & 41 & 43 & 45 & 47 & 49 \\
\hline 25 & 40 & 42 & 44 & 45 & 47 & 49 & 51 \\
\hline 26 & 42 & 44 & 46 & 48 & 50 & 52 & 54 \\
\hline 27 & 44 & 46 & 48 & 50 & 52 & 54 & 57 \\
\hline 28 & 46 & 48 & 50 & 52 & 55 & 57 & 59 \\
\hline 29 & 48 & 50 & 52 & 54 & 57 & 59 & 62 \\
\hline 30 & 50 & 52 & 54 & 57 & 59 & 61 & 64 \\
\hline 31 & 52 & 54 & 56 & 59 & 61 & 64 & 66 \\
\hline 32 & 53 & 56 & 58 & 60 & 63 & 66 & 69 \\
\hline 33 & 55 & 57 & 60 & 62 & 65 & 68 & 71 \\
\hline 34 & 57 & 59 & 62 & 64 & 67 & 70 & 73 \\
\hline 35 & 58 & 61 & 63 & 66 & 69 & 72 & 75 \\
\hline 36 & 60 & 62 & 65 & 68 & 71 & 74 & 77 \\
\hline 37 & 61 & 64 & 66 & 69 & 72 & 75 & 79 \\
\hline 38 & 63 & 65 & 68 & \begin{tabular}{|l|}
71 \\
\end{tabular} & $\begin{array}{l}74 \\
\end{array}$ & \begin{tabular}{|l}
77 \\
\end{tabular} & 81 \\
\hline 39 & 64 & \begin{tabular}{|l}
67 \\
\end{tabular} & $\begin{array}{l}70 \\
\end{array}$ & 73 & $\begin{array}{l}76 \\
\end{array}$ & \begin{tabular}{|l}
79 \\
\end{tabular} & 82 \\
\hline 40 & 65 & 68 & 71 & 74 & 77 & 81 & 84 \\
\hline 41 & 67 & 69 & 73 & 76 & 79 & 83 & 86 \\
\hline 42 & $\begin{array}{l}68 \\
\end{array}$ & \begin{tabular}{|l|}
71 \\
\end{tabular} & \begin{tabular}{|l|}
74 \\
\end{tabular} & \begin{tabular}{|l|l}
77 \\
\end{tabular} & 81 & \begin{tabular}{|l|}
84 \\
\end{tabular} & 88 \\
\hline
\end{tabular}

Table 10. Estimated femur length (FL) in mm by gestational age (GA) for males and females, standard deviations (SD). ${ }^{\mathrm{a}} \mathrm{GA}$ expressed as completed gestational weeks, e.g. 12 weeks corresponds to $12+0$ weeks or 84 gestational days. 


\begin{tabular}{|c|c|c|c|c|c|c|c|c|c|}
\hline GA (weeks ${ }^{a}$ ) & 2.5th & 5th & 10th & 25th & Median & 75th & 90th & 95th & 97.5th \\
\hline 12 & 5 & 5 & 5 & 6 & 6 & 7 & 7 & 8 & 8 \\
\hline 13 & 8 & 8 & 8 & 9 & 9 & 10 & 10 & 10 & 11 \\
\hline 14 & 10 & 11 & 11 & 12 & 12 & 13 & 13 & 14 & 14 \\
\hline 15 & 14 & 14 & 14 & 15 & 15 & 16 & 17 & 17 & 17 \\
\hline 16 & 17 & 17 & 17 & 18 & 19 & 19 & 20 & 20 & 21 \\
\hline 17 & 20 & 20 & 21 & 21 & 22 & 23 & 23 & 24 & 24 \\
\hline 18 & 23 & 23 & 24 & 24 & 25 & 26 & 27 & 27 & 28 \\
\hline 19 & 26 & 26 & 27 & 28 & 28 & 29 & 30 & 31 & 31 \\
\hline 20 & 29 & 29 & 30 & 31 & 32 & 33 & 33 & 34 & 34 \\
\hline 21 & 32 & 32 & 33 & 34 & 35 & 36 & 37 & 37 & 38 \\
\hline 22 & 34 & 35 & 35 & 36 & 37 & 39 & 40 & 40 & 41 \\
\hline 23 & 37 & 38 & 38 & 39 & 40 & 41 & 42 & 43 & 44 \\
\hline 24 & 39 & 40 & 41 & 42 & 43 & 44 & 45 & 46 & 47 \\
\hline 25 & 42 & 42 & 43 & 44 & 45 & 47 & 48 & 49 & 49 \\
\hline 26 & 44 & 45 & 45 & 46 & 48 & 49 & 50 & 51 & 52 \\
\hline 27 & 46 & 47 & 47 & 49 & 50 & 52 & 53 & 54 & 54 \\
\hline 28 & 48 & 49 & 50 & 51 & 52 & 54 & 55 & 56 & 57 \\
\hline 29 & 50 & 51 & 52 & 53 & 54 & 56 & 57 & 58 & 59 \\
\hline 30 & 52 & 53 & 54 & 55 & 57 & 58 & 60 & 61 & 61 \\
\hline 31 & 54 & 55 & 55 & 57 & 59 & 60 & 62 & 63 & 64 \\
\hline 32 & 56 & 56 & 57 & 59 & 60 & 62 & 64 & 65 & 66 \\
\hline 33 & 57 & 58 & 59 & 61 & 62 & 64 & 66 & 67 & 68 \\
\hline 34 & 59 & 60 & 61 & 62 & 64 & 66 & 68 & 69 & 70 \\
\hline 35 & 61 & 62 & 62 & 64 & 66 & 68 & 70 & 71 & 72 \\
\hline 36 & 62 & 63 & 64 & 66 & 68 & 70 & 71 & 72 & 73 \\
\hline 37 & 64 & 65 & 66 & 67 & 69 & 71 & 73 & 74 & 75 \\
\hline 38 & 65 & 66 & 67 & 69 & 71 & 73 & 75 & 76 & 77 \\
\hline 39 & 67 & 68 & 69 & 71 & 73 & 75 & 77 & 78 & 79 \\
\hline 40 & \begin{tabular}{|l|}
68 \\
\end{tabular} & 69 & 70 & 72 & 74 & 76 & 78 & 80 & 81 \\
\hline 41 & 70 & 71 & 72 & 74 & 76 & 78 & 80 & 81 & 82 \\
\hline 42 & 71 & 72 & 73 & 75 & \begin{tabular}{|l}
77 \\
\end{tabular} & 80 & 82 & 83 & \begin{tabular}{|l|}
84 \\
\end{tabular} \\
\hline
\end{tabular}

Table 11. Estimated femur length (FL) in mm by gestational age (GA) for males and females, percentiles. ${ }^{\mathrm{a}} \mathrm{GA}$ expressed as completed gestational weeks, e.g. 12 weeks corresponds to $12+0$ weeks or 84 gestational days.

\section{Data availability}

The datasets generated during and/or analysed during the current study are not publicly available due to the ethical and legal restrictions prohibiting the sharing of personal data, but are available from the corresponding author on reasonable request.

Received: 8 May 2020; Accepted: 11 December 2020

Published online: 31 December 2020

\section{References}

1. Gardosi, J., Madurasinghe, V., Williams, M., Malik, A. \& Francis, A. Maternal and fetal risk factors for stillbirth: Population based study. BMJ 346, f108. https://doi.org/10.1136/bmj.f108 (2013).

2. Lindqvist, P. G. \& Molin, J. Does antenatal identification of small-for-gestational age fetuses significantly improve their outcome? Ultrasound Obstet. Gynecol. 25, 258-264. https://doi.org/10.1002/uog.1806 (2005).

3. Ioannou, C. et al. Systematic review of methodology used in ultrasound studies aimed at creating charts of fetal size. BJOG 119, 1425-1439. https://doi.org/10.1111/j.1471-0528.2012.03451.x (2012)

4. Ohuma, E. O. \& Altman, D. G. Design and other methodological considerations for the construction of human fetal and neonatal size and growth charts. Stat. Med. https://doi.org/10.1002/sim.8000 (2018).

5. Kiserud, T. et al. The World Health Organization fetal growth charts: A multinational longitudinal study of ultrasound biometric measurements and estimated fetal weight. PLoS Med. 14, e1002220. https://doi.org/10.1371/journal.pmed.1002220 (2017).

6. Papageorghiou, A. T. et al. International standards for fetal growth based on serial ultrasound measurements: The fetal growth longitudinal study of the INTERGROWTH-21st project. Lancet 384, 869-879. https://doi.org/10.1016/s0140-6736(14)61490-2 (2014).

7. Buck Louis, G. M. et al. Racial/ethnic standards for fetal growth: The NICHD Fetal Growth Studies. Am. J. Obstet. Gynecol. 213, 441-449. https://doi.org/10.1016/j.ajog.2015.08.032 (2015).

8. Nicolaides, K. H., Wright, D., Syngelaki, A., Wright, A. \& Akolekar, R. Fetal Medicine Foundation fetal and neonatal population weight charts. Ultrasound Obstet. Gynecol. 52, 44-51. https://doi.org/10.1002/uog.19073 (2018). 
9. Heude, B. et al. Are selection criteria for healthy pregnancies responsible for the gap between fetal growth in the French national Elfe birth cohort and the Intergrowth-21st fetal growth standards?. Paediatr. Perinat. Epidemiol. 33, 47-56. https://doi.org/10. 1111/ppe.12526 (2019).

10. Cheng, Y. K. Y., Lu, J., Leung, T. Y., Chan, Y. M. \& Sahota, D. S. Prospective assessment of the INTERGROWTH-21 and who estimated fetal weight reference curve. Ultrasound Obstet. Gynecol. https://doi.org/10.1002/uog.17514 (2017).

11. Vieira, M. C., Relph, S., Persson, M., Seed, P. T. \& Pasupathy, D. Determination of birth-weight centile thresholds associated with adverse perinatal outcomes using population, customised, and Intergrowth charts: A Swedish population-based cohort study. PLoS Med. 16, e1002902. https://doi.org/10.1371/journal.pmed.1002902 (2019).

12. Marsal, K. et al. Intrauterine growth curves based on ultrasonically estimated foetal weights. Acta Paediatr. 85, 843-848 (1996).

13. Statistics on Pregnancies, Deliveries and Newborn Infants 2018. National Board of Health and Welfare. https://www.socialstyr elsen.se/globalassets/sharepoint-dokument/artikelkatalog/statistik/2020-2-6623.pdf (2020).

14. 14Rekommendationer för fetometri. Swedish Society of Obstetrics and Gynecology. https://www.sfog.se/media/98796/biometri_ 2011_sep_29_rek.pdf. (2011).

15. Salomon, L. J. et al. ISUOG practice guidelines: Ultrasound assessment of fetal biometry and growth. Ultrasound Obstet. Gynecol. 53, 715-723. https://doi.org/10.1002/uog.20272 (2019).

16. Johnsen, S. L., Wilsgaard, T., Rasmussen, S., Sollien, R. \& Kiserud, T. Longitudinal reference charts for growth of the fetal head, abdomen and femur. Eur. J. Obstet. Gynecol. Reprod. Biol. 127, 172-185. https://doi.org/10.1016/j.ejogrb.2005.10.004 (2006).

17. Johnsen, S. L., Rasmussen, S., Wilsgaard, T., Sollien, R. \& Kiserud, T. Longitudinal reference ranges for estimated fetal weight. Acta Obstet. Gynecol. Scand. 85, 286-297. https://doi.org/10.1080/00016340600569133 (2006).

18. Altman, D. G. \& Chitty, L. S. Design and analysis of studies to derive charts of fetal size. Ultrasound Obstet. Gynecol. 3, 378-384. https://doi.org/10.1046/j.1469-0705.1993.03060378.x (1993).

19. Napolitano, R. et al. Pregnancy dating by fetal crown-rump length: A systematic review of charts. BJOG 121, 556-565. https://doi. org/10.1111/1471-0528.12478 (2014)

20. Naslund Thagaard, I. et al. Dating of pregnancy in first versus second trimester in relation to post-term birth rate: A cohort study. PLoS ONE 11, e0147109. https://doi.org/10.1371/journal.pone.0147109 (2016).

21. Kiserud, T. \& Johnsen, S. L. Biometric assessment. Best Pract. Res. Clin. Obstet. Gynaecol. 23, 819-831. https://doi.org/10.1016/j. bpobgyn.2009.06.007 (2009).

22. Skalkidou, A., Kullinger, M., Georgakis, M. K., Kieler, H. \& Kesmodel, U. S. Systematic misclassification of gestational age by ultrasound biometry: implications for clinical practice and research methodology in the Nordic countries. Acta Obstet. Gynecol. Scand. 97, 440-444. https://doi.org/10.1111/aogs.13300 (2018).

23. Hoffman, C. S. et al. Comparison of gestational age at birth based on last menstrual period and ultrasound during the first trimester. Paediatr. Perinat. Epidemiol. 22, 587-596. https://doi.org/10.1111/j.1365-3016.2008.00965.x (2008).

24. Kullinger, M., Wesstrom, J., Kieler, H. \& Skalkidou, A. Maternal and fetal characteristics affect discrepancies between pregnancydating methods: A population-based cross-sectional register study. Acta Obstet. Gynecol. Scand. 96, 86-95. https://doi.org/10. 1111/aogs.13034 (2017).

25. Salomon, L. J. et al. ISUOG practice guidelines: Performance of first-trimester fetal ultrasound scan. Ultrasound Obstet. Gynecol. 41, 102-113. https://doi.org/10.1002/uog.12342 (2013).

26. Kullinger, M., Granfors, M., Kieler, H. \& Skalkidou, A. Adherence to Swedish national pregnancy dating guidelines and management of discrepancies between pregnancy dating methods: A survey study. Reprod. Health 16, 95. https://doi.org/10.1186/s12978019-0760-3 (2019).

27. Selbing, A. \& Kjessler, B. Conceptual dating by ultrasonic measurement of the fetal biparietal diameter in early pregnancy. Acta Obstet. Gynecol. Scand. 64, 593-597. https://doi.org/10.3109/00016348509156368 (1985).

28. Saltvedt, S. et al. Ultrasound dating at 12-14 or 15-20 weeks of gestation? A prospective cross-validation of established dating formulae in a population of in-vitro fertilized pregnancies randomized to early or late dating scan. Ultrasound Obstet. Gynecol, 24, 42-50. https://doi.org/10.1002/uog.1047 (2004).

29. Näslund Thagaard, I. et al. Dating of pregnancy in first versus second trimester in relation to post-term birth rate: A cohort study. PLoS ONE 11, e0147109. https://doi.org/10.1371/journal.pone.0147109 (2016).

30. Naeye, R. L. Influence of maternal cigarette smoking during pregnancy on fetal and childhood growth. Obstet. Gynecol. 57, 18-21 (1981).

31. Vesterinen, H. M., Morello-Frosch, R., Sen, S., Zeise, L. \& Woodruff, T. J. Cumulative effects of prenatal-exposure to exogenous chemicals and psychosocial stress on fetal growth: Systematic-review of the human and animal evidence. PLoS ONE 12, e0176331. https://doi.org/10.1371/journal.pone.0176331 (2017).

32. Morales-Rosello, J. et al. Birth-weight differences at term are explained by placental dysfunction and not by maternal ethnicity. Ultrasound Obstet. Gynecol. 52, 488-493. https://doi.org/10.1002/uog.19025 (2018).

33. Kierans, W. J. et al. Does one size fit all? The case for ethnic-specific standards of fetal growth. BMC Pregnancy Child. 8, 1. https:// doi.org/10.1186/1471-2393-8-1 (2008).

34. Hanley, G. E. \& Janssen, P. A. Ethnicity-specific birthweight distributions improve identification of term newborns at risk for short-term morbidity. Am. J. Obstet. Gynecol. 209, 428. https://doi.org/10.1016/j.ajog.2013.06.042 (2013).

35. Sletner, L., Kiserud, T., Vangen, S., Nakstad, B. \& Jenum, A. K. Effects of applying universal fetal growth standards in a Scandinavian multi-ethnic population. Acta Obstet. Gynecol. Scand. 97, 168-179. https://doi.org/10.1111/aogs.13269 (2018).

\section{Acknowledgements}

The study was funded by the Uppsala-Örebro Regional Research Council, Region Uppsala Research and Development Grant, Födelsefonden, the Gillbergska Foundation and the Swedish Society of Medicine. All authors have read and approved the submission of the manuscript; the manuscript is original, has not been published and is not being considered for publication elsewhere, in whole or in part, in any language, except as an abstract.

\section{Author contributions}

Study design and methodology: L.L., M.A., O.A., E.B. Project administration: L.L., E.B. Data management: L.L., M.A. Statistical analyses, figure and table preparations: L.L., M.A., L.H. Writing of original draft: L.L., M.A. Review of manuscript text: L.L., M.A., O.A., L.H., A.S., E.B.

\section{Funding}

Open Access funding provided by Uppsala University. 


\section{Competing interests}

The authors declare no competing interests.

\section{Additional information}

Supplementary Information The online version contains supplementary material available at https://doi.org/ 10.1038/s41598-020-79797-8.

Correspondence and requests for materials should be addressed to L.L.

Reprints and permissions information is available at www.nature.com/reprints.

Publisher's note Springer Nature remains neutral with regard to jurisdictional claims in published maps and institutional affiliations.

(c) (1) Open Access This article is licensed under a Creative Commons Attribution 4.0 International License, which permits use, sharing, adaptation, distribution and reproduction in any medium or format, as long as you give appropriate credit to the original author(s) and the source, provide a link to the Creative Commons licence, and indicate if changes were made. The images or other third party material in this article are included in the article's Creative Commons licence, unless indicated otherwise in a credit line to the material. If material is not included in the article's Creative Commons licence and your intended use is not permitted by statutory regulation or exceeds the permitted use, you will need to obtain permission directly from the copyright holder. To view a copy of this licence, visit http://creativecommons.org/licenses/by/4.0/.

(C) The Author(s) 2020, corrected publication 2021 